\title{
Como la [victima] española no hay. (Pistas confusas para poder seguir de cerca y entender la singular vida de un personaje social en pleno esplendor)
}

There is no one like the spanish [victim] one. (Some tracks for understanding the singular life of a social character in all its splendor)

\section{Gabriel Gatti}

UNIVERSIDAD DEL PAÍS VASCO $\cdot$ g.gatti@ehu.es

Profesor titular de sociología, Universidad del País Vasco. Dirige el proyecto "Mundo(s) de víctimas" (MICINN, CSO 2011-22451), enseña teoría sociológica e investiga sobre las formas de construcción de identidad en situaciones marcadas por fuertes vulneraciones de los derechos humanos y/o quiebras en el sentido moderno de la idea de ciudadanía. Sobre eso ha enseñado, conversado y publicado en varios lugares y momentos (EHESS, CES, UPV, UAB, UBA, Chile, Los Andes, UCLA, Stanford, UDELAR, Sorbonne Nouvelle...) y soportes, entre otros: Surviving forced Disappearance in Argentina and Uruguay (Palgrave Macmillan, 2014), Identidades desaparecidas (Prometeo, 2012), El detenido-desaparecido (Trilce, 2008), y varios artículos en más de un idioma.

RECIBIDO: 23 DE SEPTIEMBRE DE 2014 ACEPTADO: 12 DE NOVIEMBRE DE 2014

Resumen: El texto aborda, con fracaso solo aparente, una hipótesis difícil: la que sostiene que existen manifestaciones de la víctima que son específicamente españolas. Tras criticar la insuficiencia de lo que en España se está haciendo para analizar las crecientes y variadas manifestaciones de esta figura, se muestra cómo las muchas herramientas teóricas disponibles para trabajarla están fuertemente orientadas hacia dos tradiciones intelectuales poderosas pero que nos son ajenas (una francesa y francófila, otra anglófona y anglófila). Este ejercicio de teorización nacional está, evidentemente, abocado al fracaso. Pero sirve sin embargo para visibilizar algunas posibilidades interesantes, que el trabajo invita a explorar: ¿existe una víctima Latina? ¿una del Sur? ¿Hay una estética específica de la víctima en España?

Palabras Clave: Víctima, aspectos sociales; humanitarismo; tradiciones intelectuales.

\begin{abstract}
The text deals, with an only apparent failure, a really difficult hypothesis: one that argues that there are manifestations of the victim which are specifically Spanish. After criticizing the inadequacy of what in Spain is being done to analyze the growing and varied manifestations of this figure, this work shows how the many theoretical tools available to work it are strongly oriented towards two powerful intellectual traditions (a French and Francophile one, an Anglophone and Anglophile one), but both them alien. This exercise of national theorizing is obviously doomed to failure. But nevertheless it serves to make visible some interesting possibilities: is there a Latina victim? Is there a South victim? Is there a specific aesthetic of victims in Spain?
\end{abstract}

Key Words: Victim, Social Aspects; Humanitarianism; Intellectual Traditions 
"Cada sociedad tiene sus víctimas". Esta sentencia, paráfrasis de otra que propuso Serge Paugam (1996) — “cada sociedad tiene sus pobres" - nos acerca al lugar al que quisiera llegar en este texto: intentar dar fundamento a un argumento que permita, al final, decir que existe una víctima española. Aviso desde ya que no lo lograré. Ni aquí ni en otros textos. No obstante, intentaré dar cuenta de las razones que explican que haya surgido esa pregunta y que hacen, en algún punto, legitima la aspiración de dar con esa víctima de tonos locales tan marcados. Aunque no la hayamos encontrado ${ }^{1}$ me importa dar cuenta de las razones de la búsqueda, y es muy poco lo que ahora me molesta de que la hipótesis - que hay una víctima españolatermine siendo nula.

O más o menos, pues la duda flotará sobre las conclusiones del texto ya que algo de eso - víctimas de aquí- hay. Es cierto que eso que hay no será tan rojigualdo como puede deducirse del primer párrafo, que eso quizás merezca otro nombre, más generoso con otras geografías (víctimas del Sur), y con otros procesos histórico-sociales (víctimas transicionales, víctimas periféricas, víctimas subalternas). Es cierto incluso que quizás lo que el trabajo que está detrás de este texto intuye es que, más que buscar teorías nacionales, lo que se precisa es voltear lo heredado para pensar al sujeto marcado por el dolor y adaptarlo a tiempos en los que los personajes dolientes ocupan lugares centrales de nuestras geografías emocionales, morales, estéticas y políticas. Dudas. Sea como sea, lo que sí quiere mostrar este texto es la distancia existente hoy entre los aparatos teórico-metodológicos disponibles para analizar sociológicamente la figura de la víctima y la forma que ésta adopta. Así es: aquí desde donde escribo, la España de los comienzos del Siglo XXI, también en lugares en los que trabajé hasta hace poco (Argentina y Uruguay) (Gatti, 2014), se asiste a un espectáculo denso, el de un mundo de vida en explosión: el campo social de las víctimas. Es un mundo de vida con dolientes, con expertos, con estéticas, con circuitos de poder, con formas de entender el cuerpo... singulares, muy efervescente en materia legislativa, en movimientos, en lenguajes, y en formas de expresión artística. Muy rico. Pero cuando buscamos material teórico par pensarlo no encontramos siempre el adecuado. Fuera de trabajos terapéutico-curativos, o de descripciones estadísticas, el material disponible, siendo magnífico, propone herramientas con señales que lo orientan hacia otras tradiciones, sensibles unas - de acento francés - al ciudadano pauperizado, sensibles otras — de sonoridad más anglosajona - a una víctima abordada como manifestación

\footnotetext{
${ }^{1}$ El plural, lejos de ser mayestático, quiere reconocer las condiciones de posibilidad de la producción de este texto, que es de autoría colectiva, la del equipo de investigación que coordino alrededor del Proyecto "Mundo(s) de víctimas. Dispositivos y procesos de construcción de la identidad de "la víctima" en la España contemporánea" (CSO 201122451). Pueden encontrarse más informaciones en la web del proyecto. Algunas de las ideas de este texto fueron primero trabajadas junto a David Gómez Ruiz, aunque luego fueron desarrolladas con el equipo del proyecto en conjunto o en solitario. Un primer esbozo de este trabajo lo presenté en el congreso de la RAM (Reunión de Antropólogos del Mercosur) que se celebró en Córdoba (Argentina) en julio de 2013; un segundo en el seminario "Sangre y filiación en los relatos del dolor", que se organizó en mayo de 2014 en Bilbao. De ambos foros beben muchos de sus párrafos.
} 
universal del individuo en posición doliente. Ese material es magnífico, sí. Pero no encaja del todo con la textura de la evidencia empírica que hemos encontrado en España o en el sur o, quizás, en las periferias emergentes, o incluso en el mundo contemporáneo, así, in toto.

"Sociólogo ante problema teórico", pues. Arrancaré el texto alejándome de mi disciplina y paseándome por un producto cultural reciente y muy local, el documental Un largo invierno (Arabia, 2010), para con su ayuda proponer algunas claves de análisis que singularizan la "manera nacional" de representar la figura de la víctima. El propio análisis del documental sobre la presidente de la Asociación 11M, afectados por el terrorismo, Pilar Manjón, ayudará a dar el segundo y tercer pasos del argumento de este texto: mostrar la insuficiencia de lo que en España se está haciendo para analizar un fenómeno, la vida social de las víctimas, efervescente y profuso; mostrar lo nacionalmente condicionadas que están las herramientas teóricas dominantes en la materia, una producción que de tan descomunal, resulta, es cierto, difícilmente clasificable pero que si se intenta muestra que se bifurca en dos líneas fuertes, una francesa y francófila, solidarista y colectivista, y otra anglófona y anglófila, universalista y sensible al dolor individual. Ambas contienen productos excelentes pero son en mucho ajenas a lo que hoy el trabajo de campo dice que es la vida social de las víctimas. El último punto del argumento, su cierre, se servirá bajo forma de algunas preguntas: esa vida social, densa, efervescente, profusa ¿es propia del caso español? ¿Qué teorías(s) necesita? ¿Es necesario ampliar el campo de batalla, sea en el espacio (otras regiones, el sur quizás) sea en el tiempo (toda una época, la nuestra, que acaso merezca el nombre de era de las víctimas)?

\section{Pilar, mujer de negro. Dos notas nada profesionales sobre Un largo invierno}

Un largo invierno es un documental sencillo. Lo dirigió Sebastián Arabia en 2010 y lo sostiene la imponente presencia de Pilar Manjón. Me interesa aquí un solo asunto: el cuerpo, bajo dos declinaciones, el cuerpo común de un sujeto ordinario, marcado para presentarse como el cuerpo de una víctima; el cuerpo colectivo, ciudadano, poblado ahora de esos sujetos marcados.

Los ojos, siempre ojerosos, de Pilar, siempre amenazando un estallido que no llega, el cuerpo marcado, que se presenta como el cuerpo de todas las víctimas, las del $11 \mathrm{M}$, las de cualquier causa. Primeros planos de su rostro, de sus manos nerviosas jugando con el anillo; del tatuaje sencillo con la firma de Daniel, el hijo asesinado el 11 de Marzo de 2004 en uno de los trenes que aquella mañana rondaba la estación de Atocha. "Parece de boli", me dijo². Y la ropa negra, siempre el negro. Desde entonces, el de Pilar Manjón es un cuerpo de víctima, es ésa su identidad pública: ciudadanovíctima. No abandona lo que fue (ciudadana), al contrario, lo potencia a partir de su dolor. Su historia personal es colectiva, sus marcas son compartidas. "Su subjetividad y singularidad emergen como un caso paradigmático. La vivencia individual, privada, se

${ }^{2}$ En la entrevista que le realicé junto a otros miembros de la junta directiva de la asociación en el contexto del trabajo de campo del proyecto "Mundo(s) de víctimas". 
articula con una problemática y un reclamo público" (Calzado, 2014). Cuerpo de todos y para todos. Paradójico: sus marcas de dolor (intransferibles y únicas) son las que la convierten en víctima, y esa condición (intransferible y única) la une a una comunidad de sujetos que, ellos también, muestran las llagas de sus dolores, intransferibles y únicos. Extraña comunidad, de seres separados (Das, 2008; Butler, 2006). El 15 de mayo de 2013 David Casado (ver su artículo en este mismo dossier ) recogió en el diario de campo del proyecto en que se apoya este texto ${ }^{3}$ la entrevista a las hijas de dos personas asesinadas por una célula nazi en Alemania. David anotat:

Lo interesante aquí me parece la foto en la que una muestra tatuado en el brazo el nombre de su padre. No son hermanas pero ahora dicen compartir un destino común.

Así es, en estas víctimas ciudadanas, la marca, una marca autoinfringida — no un número de campo, ni una herida de un golpe, un terremoto o un accidente, sino la cara del padre asesinado o de la madre maltratada, la fecha de su muerte, o de su desaparición, su firma - les une a otros que, como ella, tienen marcas tan (im)propias y exclusivas.

Por eso Pilar Manjón no habla nunca en nombre propio, ni siquiera solo en el de las víctimas de la Asociación que preside o del colectivo que integra. Está en lo público desde el dolor, desde la condición de víctima misma, algo que antes excluía, precisamente de la posibilidad de pertenecer a esa instancia, lo público: la víctima era una condición que expulsaba de la ciudadanía, conducía a un territorio más allá, el de los héroes y los mártires, el del sacrificio. Sublime pero fuera de la ciudad. No así ahora: Pilar Manjón es una ciudadana y así habla. En la impactante y directa declaración que hizo en el Parlamento español, y alrededor de la que orbita parte importante del documental, comienza así, con voz temblorosa: "Mi nombre es Pilar Manjón y vengo en representación de la Asociación 11M, Afectados por el terrorismo, de las víctimas, heridos y sus familias (...). Quiero dejar constancia de la firme voluntad de la asociación a la represento para transmitir expresamente el sentir de un colectivo, nunca el mío propio"s. Habla pues un cuerpo doliente ("hablo desde el dolor", "represento el dolor de las familias", "la voz de las víctimas es nuestra") que representa a toda la ciudadanía.

Frente a otras narrativas en las que las víctimas tomaban la palabra por su dolor, sí, pero ese dolor las sacaba del común, las hacía excepcionales (así las víctimas del Holocausto, así incluso las del terrorismo hasta hace poco) el cambio es radical. Aquí, Pilar Manjón, ojerosa, de negro, marcada, tatuada, lúcida, habla ante el Parlamento desde un lugar distinto: un sujeto ordinario que sufrió un suceso extraordinario. Es una

\footnotetext{
${ }^{3}$ El diario de campo es una herramienta de investigación común en ciencias sociales que en este caso, el proyecto Mundo(s) de víctimas, tuvo como característica singular que fue colectivo, simultáneo y compartido.

${ }^{4}$ En castellano se da cuenta de la noticia en El País de ese mismo día (Más detalles figuran aquí.

${ }^{5}$ La declaración fue realizada ante la comisión de investigación del 11M del Parlamento Español, en diciembre de 2004. Puede visionarse aquí.
} 
ciudadana afectada. "Cualquiera pudo viajar en ese tren. Solo el azar dispuso que fuésemos nosotros", dice, exhibiendo una lógica en la que resuena la forma de representarse y presentarse de otros colectivos de víctimas en España: "Todos íbamos en ese tren" (del propio 11-M), "Porque podíamos haber sido cualquiera" (lema de algunas convocatorias del colectivo de víctimas del metro de Valencia, el 3 de julio de 2006), "A ti te puede pasar" (moto común en los llamados de las asociaciones de familiares de bebés robados). Gente ordinaria, usted, yo, ella, atravesada por una catástrofe.

El 21 de junio de 2013, en el diario de campo de la investigación, mientras me dirijo temprano y en tren a la sede de la Asociación 11-M, afectados por el terrorismo, en Santa Eugenia, periferia obrera de Madrid, anoto:

$\mathrm{Ni}$ es 11 de marzo, ni 3 de julio, pero cuando voy a ver a un ciudadano-víctima, cada acción que conduce hacia él o ella, por rutinaria que sea, cuanto más rutinaria más, hace a su condición de "víctima ordinaria": la red de llamadas para acceder, el medio de transporte con el que me muevo... Me rodean, soy, son, ciudadanos normalitos y en este contexto los pienso como víctimas. Las dos condiciones eran opuestas antes; hoy son casi sinónimos: ciudadano y víctima.

Atocha, el Pozo, Santa Eugenia, Leganés... Son las 8:52, la gente tiene sueño aunque hace un día precioso. Nadie mira a nadie, somos un mero agregado; este emigrante se baja aquí, este estudiante piensa en aquello, el gafipasti lee algo de ciencias sociales, y los cuatro pakis que suben en Atocha están de turismo por la ciudad mientras esa señora va a no sé dónde. Y yo. No sé nada de nadie ni nadie sabe nada de mí. Ciudadanos comunes. Y click: accidente, atentado, catástrofe, desastre. Lo que sea. El agregado se hace comunidad y la conexión, aunque circunstancial, es poderosa y para siempre. Comunidad de sujetos marcados. Pero no obstante anónimos, ciudadanos, comunes y silvestres. "Todos íbamos en ese tren", "Todos somos víctimas".... No me resuena esto si merodeo cerca de víctimas de ETA o del GAL, ni cuando hice trabajo con familiares de detenidos-desaparecidos en Argentina o en Uruguay. Estaba con aristocracias, con personajes extraordinarios. Ahora no: lo ordinario es excepcional y oprime.

\section{De un campo que fue tranquilo y que (en España) ahora tiembla (y para el que además la teoría falta y la que hay falla)}

La intensidad, la corporalidad, la manifestación pública del dolor, la unión entre víctimas de distintos orígenes, la facilidad con la que se establece la conexión entre ellas... En distintos contextos esas circunstancias se repiten: en los grupos de discusión que organizamos entre víctimas de distinto tipo, tan distintas que una racionalidad ajena a la actualidad de la figura aconsejaría abandonar la idea de proponer un diálogo 
entre ellas, la conexión sin embargo se establece fácil y fluidamente, independientemente de la causa del dolor y del tipo de víctima del que se trate ${ }^{6}$. Él sufrimiento mismo, las marcas que eso deja en el cuerpo, los reclamos a los que esa condición de doliente habilita parecen ser motivos suficientes para buscar lazos y que la empatía se establezca. En la escena política y mediática son también comunes puestas en escena compartidas del dolor propio, a las que las víctimas acuden sin apellidos, sin distinciones. Solo como tales víctimas. Así: en el acto de aprobación del estatuto de la víctima del delito, en julio de 20147; en la celebración del día de las víctimas del terrorismo, en junio de este mismo año; en los testimonios de víctimas en escuelas vascas, que se han multiplicado en el último lustro...

Pero los análisis sin embargo apuntan en otra dirección. O en ninguna. Abundan trabajos orientados por una perspectiva clínica, o con una marcada vocación reparadora, producidos por regla general por los propios profesionales implicados en los complejos mundos sociales construidos en torno a las víctimas (Pérez Sales y Navarro, 2007; Beristain y Páez, 2000), pero que no cuestionan ni la víctima ni su genealogía. Tampoco son pocos los productos intelectuales que proceden de la filosofía política (sobre lo humano en demolición), de la ética (Mate, 2002) o de cierta antropología simbólica (siempre con Girard (1982) en el horizonte de referencias), que atienden a las raíces antropológicas de la figura: la universalidad funcional del mártir, del héroe, o del chivo expiatorio, o la raíz religiosa de su construcción. Análisis imprescindibles, pero en muchas ocasiones demasiado alejados de las demandas de historicidad y de empiricidad de un sociólogo. Si buscando esto nos acercamos a estudios más cercanos al momento presente, no son pocos los que tienen la de víctima entre sus palabras clave: trabajos en ciencia política sobre las víctimas del terrorismo (Lllera, Retortillo, 2004), en antropología social sobre el duelo (Sánchez-Carretero, 2006) o sobre las exhumaciones de las fosas de la represión franquista (Ferrandiz, 2013), investigaciones multidisciplinares sobre la violencia machista (entre otros, Rodríguez Yagüe, 2000; Casado y García Selgas, 2010). Fuera de un cierto y analíticamente muy irrelevante coyunturalismo al que ciertas disciplinas propenden, ninguno se acerca a la víctima, sino a $s u$ víctima específica, de modo que la figura resulta ser apenas una variable dependiente del que constituye el tópico objeto de atención de estos trabajos (terrorismo, memoria, violencia...), protagonista pero a lo sumo como parte del elenco de secundarios.

Insuficiente para entender la convulsión que parece atravesar el campo de las víctimas en España: cada vez hay más, cada vez hay de más ¿Por dónde pensarlas? Hace ya algunos años, en 1997, para interpretar la comparecencia masiva al espacio

\footnotetext{
${ }^{6}$ Fueron tres grupos organizados entre junio y octubre de 2013 en Bilbao y Madrid. En todo ellos se pusieron en diálogo víctimas de orígenes diversos, con posiciones muy heterogéneas en relación a la causa, intensidad, visibilidad mediática y política: víctimas del 11M, de robo de bebés, de la represión durante el posfranquismo, de desahucios, de accidentes de tráfico, de violencia de género, de siniestros aéreos, y un largo etcétera.

${ }^{7}$ Consúltese la nota y las fotos de la presentación pública del texto aprobado en la página web del Ministerio del Interior.
} 
público de algunas naciones europeas y en los años finales del siglo XX de ciudadanos que se reclamaban "víctimas del Holocausto", el sociólogo belga Jean Michel Chaumont propuso como clave de análisis el concepto de concurrence, competencia. Alcanzó un considerable éxito, pues ayudaba a visualizar los movimientos de sujetos que reclamándose con el derecho a ser reconocidos bajo la condición de víctima acudían a una escena pública que se saturó de dolientes que aspiraban al capital simbólico asociado a ella, en particular de víctima del Holocausto. Había motivos para competir: la de víctima era una condición que había escalado muchas posiciones en la pirámide de prestigio de las sociedades centrales, tantas que devino un lugar social confortable.

En España, el que podría llamarse el "espacio social de las víctimas" ha funcionado con gran estabilidad, incluso con inquietante quietud, hasta hace bien pocos años. Pero en la última década, digamos que en el siglo XXI, cuando la figura ha ganado centralidad, cuando ocupa espacios cada vez más relevantes en la escena social y en las agendas política, jurídica, legislativa y mediática, se ha abierto el espectro de situaciones que esa figura comprende: no merecen hacer suyo el término solo las víctimas de ETA, sino también de la violencia machista, las de la Guerra Civil, las del 11-M, las del Yak-42, las de la apropiación de bebés, las del yihadismo, las de accidentes de aviación, las de la represión franquista, las de la crisis, las de una inundación, las de... Las hay a espuertas. Y no cesan de acudir al espacio público sujetos que reclaman el derecho a hacer suyo ese sustantivo, víctima: trabajadores precarios, desahuciados, sin papeles, estafados por la banca... Si cuando pensamos en las políticas del reconocimiento o de la identidad lo que nos viene a la mente son las minorías de género o étnicas, ahora parece que también encuentran su semillero en las situaciones de vulnerabilidad.

¿Cabe para esa España aplicar la hipótesis de Chaumont? Sí, aunque con matices: refleja adecuadamente lo que sucede en un espacio social constantemente removido por la revelación periódica de nuevas demandas de reconocimiento de la condición de víctima; pero sin embargo no recoge lo que para Chaumont no era un problema: la variada naturaleza de las causas que están tras esos reclamos. Para eso, la concurrencia, más que evocar la competencia por el reconocimiento del dolor y de la condición de víctima, refiere a la de la multitud ocupando (o aspirando a hacerlo) un mismo espacio, el de las víctimas, pleno de demandas de naturaleza diversa.

Esas demandas han ido cuajando incluso institucionalmente; baste ver la profusión normativa de los últimos años, reflejo fiel del grado de institucionalización de una figura cada vez más central y cada vez más diversa: la promulgación de la Ley 32/199 de Solidaridad con las Víctimas del terrorismo marca el punto de partida; 2012, con el decreto de la Comunidad Autónoma del País Vasco sobre "Víctimas de vulneraciones de derechos humanos y sufrimientos injustos producidos en un contexto de violencia de motivación Política", o 2014, con la aprobación del "Estatuto de la víctima del delito" o la Ley de la Memoria Democrática en Andalucía, el de llegada. Y en medio, un período de siete años - el gobierno del Partido Socialista Obrero Español 
presidido por José Luis Rodríguez Zapatero (2004-2011) — en el que se agitó la escena pública con una prodigalidad inaudita de normativas sensibles a poblaciones, a colectivos, a situaciones de las que vulgarmente llamamos "vulnerables": la ley contra la violencia de género ${ }^{8}$, de 2004, dio visibilidad a lo que la ley nombra y a sus víctimas; la ley de dependencia, de $2006^{9}$, problematizó la cuestión de las cadenas de cuidado y de vulnerabilidad; la ley de memoria histórica, de $2007^{10}$, no solo problematizó la idea de "política de la memoria", no solo llevó, aunque tímidamente, a la letra de la ley palabras difíciles como "desaparecido" o "fosa común", sino que abrió el camino -o culminó uno ya abierto- para que (re)naciesen las víctimas de la Guerra Civil y de la represión franquista; la ley de reconocimiento de víctimas del terrorismo, de 2011 ${ }^{11}$, que abrió el horizonte del concepto de víctima de terrorismo a muchas situaciones distintas a las que contemplaba la vieja ley de 1999, que consideraba apenas a las de la acción de ETA...Y más.

Tal abundancia normativa agitó muy considerablemente la escena pública y contribuyó a alimentar la preeminencia que hoy sin duda tiene un personaje ya muy instalado. Es desde entonces que en España se abrió lo que podríamos llamar el nuevo espacio de las víctimas, del que destaco tres características:

1) Es un espacio habitado por un sujeto ordinario. El viejo espacio de las víctimas se ordenaba en torno a un imaginario de esta figura que hacía de ella una singularidad, un lugar especial; esto es, un sujeto marcado por un hecho extraordinario, y un sujeto por todo eso excepcional (Wieviorka, 2003). Tal excepcionalidad armonizaba con la naturaleza de los tableros en los que se dirimían sus significados: los de la política o los de la religión, trascendentes, aristocráticos, serios, circunspectos, espectaculares (Dodier y Barbot, 2009). También con los nombres, atributos y adjetivos de sus personajes centrales: héroe, mártir, sacrificio, honor, lucha, luchador... Pero cuando el espacio de las víctimas se abre, entran en él exigiendo ser reconocidos sujetos dañados con marcas de otros orígenes: ya no necesariamente son héroes o mártires; al contrario, son sujetos comunes. Ciudadanos víctima.

2) Las causas de ingreso a ese espacio se pluralizan. Y si son ordinarios los sujetos lo son o pueden serlo los motivos desde los que pensar que se debe ser reconocido como víctima. Motivos trascendentes (Guerra Civil, Franquismo, 11M, desaparición forzada de personas, tortura policial, persecución y amenazas, apropiación de niños, yihadismo, desplazamiento forzoso...) se mezclan con otros propios del orden de lo cotidiano (accidentes domésticos, mala praxis médica, precariedad laboral,

\footnotetext{
${ }^{8}$ Ley 1/2004 de Medidas de Protección Integral contra la Violencia de Género.

${ }^{9}$ Ley 39/2006 de Promoción de la Autonomía Personal y Atención a las personas en situación de dependencia y a las familias de España.

10 Ley 52/2007 por la que se reconocen y amplían derechos y se establecen medidas en favor de quienes padecieron persecución o violencia durante la guerra civil y la dictadura.

11 Ley 29/2011 de Reconocimiento y Protección Integral a las Víctimas del Terrorismo.
} 
intoxicaciones, vulnerabilidad social y dependencia, estafa bancaria, accidentes de coche, de $\operatorname{tren}^{12}$, de metro ${ }^{13}$, de avión $\left.{ }^{14} \ldots\right)$. La víctima es multitud, los dolores se desordenan, se rompen viejas jerarquías. Al afirmar esto no hago ningún juicio moral ni inició un argumento que se quiera que desemboque en el rechazo de una situación en la que el dolor se ha banalizado. Tampoco se pretende abrir la vía para desarrollar el reclamo de reconocimiento de sufrimientos hasta ahora olvidados. No. La vía ya está abierta y es ya un dato empírico que hoy, en España, hay víctimas por doquier, y que ese dato es la señal de apertura de un espacio ya nada restrictivo, donde cabe mucha más gente que la que antaño cabía. En el nuevo espacio de las victimas la concurrencia sí es masiva.

3) El espacio de las víctimas se ha profesionalizado y ritualizado. Con el sujeto "víctima" consolidado, el espacio que habita se cristaliza, invitando a un ancho abanico de profesionales de la asistencia, la gestión, la reflexión sobre el dolor, a ingresar en él para ejercer su oficio: historiadores de la memoria, psicólogos, antropólogos sociales, archiveros, psiquiatras, gentes de la ética y la teología, profesionales del derecho, victimólogos, performers, antropólogos forenses... Son nuevos oficios, soportados por "técnicas morales" (Gatti, 2013), que en España se desbocan a partir de la "era Zapatero", una etapa, decíamos, pródiga en la producción de normas sensibles al dolor y productora de espacios para su gestión.

El espacio de las víctimas es un espacio habitado y plural. La figura de la víctima, antaño clara, es ahora polisémica; el territorio que perfila, un lugar en cierta medida confortable y abierto, donde habitan sujetos muy plurales: afectados por el Terrorismo, antiguos combatientes, viejos luchadores, gudaris, mujeres maltratadas, torturados, madres de bebés apropiados en hospitales públicos o en hospicios, accidentados, desahuciados... Espacio ancho, sí, de complicada regulación, lleno de sujetos que lo habitan y con otros llamando a la puerta. Se confunde con la ciudadanía. Si como decía al principio, cada sociedad tiene sus víctimas, esa - plural, multitudinaria...- parece ser la de la España de hoy.

¿Tengo teorías para pensarla?

${ }^{12}$ En relación al accidente en verano de 2013 de un tren en las cercanías de Santiago de Compostela.

${ }^{13} \mathrm{El}$ accidente del metro de Valencia del 3 de julio de 2006 del que surgió una asociación, Asociación de Víctimas del Metro 3 de Julio (AVM3J), que se ha constituido, pasados los años, en una referencia en cuanto a la capacidad de movilización ciudadana de las víctimas de raíz no política.

${ }^{14}$ En referencia al accidente del vuelo de la compañía aérea Spanair JK 5022 en el aeropuerto de Madrid, Barajas, en agosto de 2008 en el que murieron 154 personas. 


\section{La víctima, un personaje universal pensado desde tradiciones locales}

La víctima es un personaje universal, que ha alcanzado rango de estrella en el firmamento de la era humanitaria (Fassin y Rechtmann, 2011). Las hay de todo y por todas partes; alrededor de ellas se estructuran políticas públicas locales e internacionales; son la coartada para el despliegue de la enorme red de asistencia del humanitarismo internacional; son el nombre que hoy toman los vulnerables, los dolientes, los parias... Son, sí, competidores fuertes de algunas conformaciones históricas del ser humano que parecían insuperables e inderribables: el sujeto histórico, el individuo, el ciudadano. Figura complicada de definir para un científico social, pues cada una es única (el dolor no se compara, decimos) aunque a veces trabajen como conjunto, pues componen actores colectivos (asociaciones, grupos de intereses, manifestaciones...)... pero no como los otros. Es un sujeto que sufre, un individuo concreto que padece, un humano en posición de despojo y es también —el sociólogo que soy no puede dejar de verlo- una construcción histórica y colectiva. La figura, por absoluta que parezca, requiere que nos acerquemos a ella con prudencia, la propia de las cosas que merecen relativizar nuestras convicciones. Traduzco esa prudencia en tres asertos.

El primero se refiere a la universalidad de la víctima. Toda sociedad problematiza, objetiva y trata de un modo $\mathrm{u}$ otro a aquellos sujetos que son pensados como sufrientes, como alcanzados por un daño del que no son responsables (o del que son inocentes) y que merecen por eso atención (cuidado, compasión, piedad, expulsión...) del común, del que por ese daño que padecen fueron excluidos.

El segundo pelea con el primero, o lo acompaña para situarlo. Afirma la historicidad de la víctima. Así es, la víctima ocupa lugares cambiantes. Si en la premodernidad designaba un sujeto excepcional -mártir o héroe-, un otro radical respecto al que es posible, deseable y aconsejable identificación, solidaridad o piedad, pero con el que no se comparte sentimiento de co-pertenencia a un todo orgánico común (Dodier y Barbot, 2009) hoy la topología de la figura ha cambiado: la víctima es un otro cercano, un uno mismo transformado en sufriente por efecto de un desastre, o de un ejercicio de violencia natural o social inesperado y/o inadmisible, que uno mismo podría haber sufrido. Hoy, en la "sociedad de las víctimas" (Erner, 2007), todos lo somos.

Y el último aserto baja con la víctima a los territorios específicos donde se la cuida, se la piensa, se la administra. Este tercer aserto habla del carácter local de cada tipo de víctima y sostiene que en la contemporaneidad, la manera de tratar (léase, de gestionar, de representar, de objetivar) esta figura responde a distintas tradiciones nacionales de administración y de gobierno tanto del común como sobre todo de lo que no lo es, es decir, de administración y de gobierno de la ciudadanía y de sus bordes: vulnerables, pobres, excluidos, expulsados... En esa genealogía, la del paria, se inscribe la víctima y como otros ocupantes de esa saga (el pobre, el carenciado, el excluido, también el extranjero...) está en el borde, pero no es un sujeto exterior a la sociedad (Simmel, 1998): es el último extremo de la vida social, pero es un con parte, y 
merece por eso que se trabaje sobre él (moralmente, educativamente, sanitariamente, policialmente...) para integrarlo, para acercarlo a un núcleo - ese lleno de ciudadanos normales - del que, al menos teóricamente, es potencialmente miembro. Hay incluso, dice Simmel por letra de Paugam y Schultheis (1998), principios nacionales de asistencia. Dos destacan: el del solidarismo francés, colectivista, que piensa al pobre y a la pobreza (y por extensión, en mi hipótesis, a todo aquel que se emplace en los límites del común) como una situación en una estructura de posiciones a la que se acerca para modificar y así equilibrar; el del asistencialismo organizado anglosajón, privatista, que trabaja con el pobre y la pobreza como siendo una condición en una pirámide de capacidades en la que interviene para paliar diferencias. El marginal naturalizado frente al pobre ciudadano (Merklen, 2010), bien distintos pero ambos dentro de la sociedad tanto del solidarismo totalizante del uno como de la caridad bien ordenada del otro.

\subsection{La aproximación francesa a la víctima}

Convienen ser precavidos: es difícil decir que existe una única "aproximación francesa a la víctima". No obstante, es cierto que a partir de una tradición intelectual en la que rigen ciertas ecuaciones, desde "Francia" se proyecta sobre las víctimas un aparato que las imagina como figuras ligadas a la ciudadanía, el vínculo social, la asistencia social, las políticas públicas y sus burocracias... Esas ecuaciones, que formulo de un modo indebidamente maniqueo ${ }^{15}$, son: la equiparación entre sociedad y EstadoNación y entre actor social y ciudadano; la convicción de que el sentido de la sociedad apunta al mantenimiento del vínculo social.

En contextos regidos por esas ecuaciones - llamémosles "sociedades modernas" o "sociedades à la francesa" - a los sujetos en posición doliente no se les expulsa sino que se les asiste para reintegrarlos al conjunto: la integración de individuos desafiliados y la administración de poblaciones vulnerables es, ciertamente, una de las características fuertes de esta modalidad del estar juntos. En el marco con arreglo al que se ordenan estas operaciones de asistencia es que propongo pensar que se imaginan hoy las que a partir de esta aproximación se entienden como víctimas.

En una situación social perfecta, la totalidad de sus ciudadanos están integrados. De existir sujetos en posición vulnerable, el Estado trabaja para re-integrarlos, para devolverles a su estatus de ciudadanos/as. Es ese el proyecto solidario del Estado social, con arreglo al que los vulnerables, en cualquiera de su declinaciones (pobres, precarios, paupers, víctimas), son los ocupantes de situaciones pasajeras, de lugares a abandonar; nunca definen una identidad, jamás puede pensarse que esos términos refieran a una condición indeleble en el sujeto que es nombrado por ellos. Pero cuando los vulnerables superan los contenedores de ese proyecto, el sueño de la sociedad moderna, à la francesa, se desborda. Y si los vulnerables demandan ser reconocidos en sus dolores y/o insuficiencias, la ciudadanía y sus dignidades entran en default. $\mathrm{O}$ así se lee: ante la avalancha de ciudadanos que se presentan como víctimas, de sujetos que

${ }^{15}$ Para un desarrollo mucho más preciso, véase Gatti (2008) y sobre todo las fuentes de las que allí bebo. 
ingresan en la vida social, la vida política, la vida jurídica, desde dolores privados, la reacción (reacción que es política pero que aquí interesa en sus manifestaciones analítico-académicas, intelectuales si se quiere; ver en ese sentido los trabajos de Wieviorka, 2003; Garapon y Salas, 2007; Erner, 2007; Chaumont, 1997, entre otros) es de profundo recelo, con el desprecio en el extremo y la denuncia o el análisis en clave de sospecha como el mejor resultado: la víctima, se dice, quita espacio, confronta, rivaliza, polemiza, y hasta disputa, la posición central del que ha sido el soporte subjetivo del lazo social moderno, de la sociedad à la francesa, el ciudadano. La víctima representa, se afirma, una "identidad negativa", que impide la ciudadanía y dificulta el funcionamiento del engranaje de la vida colectiva. Es señal de una "ciudadanía inmadura", sin responsabilidad, asistida, asentada en la queja (Wieviorka, 2003). La denuncia, ahí, es una primera posibilidad. La otra, análisis que remarcan lo que en esta figura se equipara a cualquier otro actor social, con sus mismos intereses y parecidas racionalidades (Lefranc y Mathieu, 2009), o que destripan el enorme aparato que constituye - y existe gracias a - las víctimas: el mundo humanitario (Agier, 2008), sus experticias y burocracias (Latté, 2008), en fin, los dispositivos que históricamente han participado de la construcción de este competidor del ciudadano.

Argumento poderoso. Cré́ble. Racional. Cartesiano. Pero sin embargo insuficiente para entender la intensidad de una figura de densidades específicas, que pone en juego aspectos otros que los que caracterizan a un actor social convencional: el lenguaje del cuerpo, la especificada de la palabra asociada al dolor, la dificultad de analizar el caso por caso...

\subsection{La aproximación anglosajona a la víctima}

A diferencia de la anterior, la aproximación anglosajona no aborda la víctima como un constructo social e histórico sino como una condición humana - por tanto, universal y ahistórica - de la que lo característico es la experiencia individual de dolor y sufrimiento y, en su dimensión social, una mirada entre compasiva y clínica, propia de una cierta tradición liberal en la gestión de la cuestión social ${ }^{16}$. La aproximación anglosajona se acerca entonces a la víctima a partir de la reflexión sobre lo humano, o mejor dicho, de la reflexión sobre la condición antropológica en situación vulnerable. El precio a pagar es alto, la deshistorización y la naturalización; pero también es alta la ganancia: sensibilidad por el sujeto sufriente, por lo específico de su lenguaje y por sus capacidades de articular comunidad y sentido (Das, 2008).

Ciertamente, la aproximación anglosajona a la víctima se muestra más cercana y sensible - tanto a las dimensiones individuales de la figura como a la singularidad de un dolor que es, en gran medida, intransmisible. El dolor del individuo sufriente, su comunicabilidad, son, por ello, parte importante de los lugares de interés de esta aproximación. En el acercamiento anglosajón, la víctima es en efecto un sujeto que hace su agencia en el dolor y que pese a que no es transmisible, lo comunica y hace

${ }^{16}$ Que tiene hoy una de sus manifestaciones más elaboradas en las muchas propuestas de trabajo que en diversos campos se sostienen sobre el concepto de cuidado (Laugier, 2012). 
comunidad —comunidad de dolor (Das, 2008; Jimeno, 2008) - desde esas experiencias (el cuerpo roto del sufriente, su lenguaje quebrado) que, a priori, niegan incluso su posibilidad (Gatti, 2010).

Poderoso. Sensible. Intenso. También creíble. Pero insuficiente para entender la historicidad de una figura de calidades muy contemporáneas, difícilmente desligable de la expansión planetaria de la sensibilidad por lo humano descompuesto. Aunque distinta, la víctima es un actor como otros y su efervescencia y profusión han de ser situadas en contexto.

\section{Regreso sobre la evidencia empírica... ¿ ¿Desde dónde pensar la víctima que falta por pensar?}

${ }_{\mathrm{C}}$ Puede trabajarse en España con estas tradiciones? ¿Puedo entender a Pilar

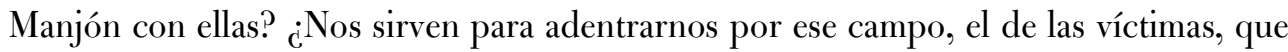
fue tranquilo y que en España ahora tiembla de tantos que concurren en él? Solo parcialmente. $\dot{\mathrm{c}}$ Amerita ese campo entonces ponerse manos a la obra para hacer el esfuerzo de construir una "solución nacional"? No lo sé... no lo creo. Pero debo hacerme la pregunta.

De lo dicho hasta ahora parecería que efervescencia, profusión y confusión entre víctima y ciudadano son tres de los datos fuertes de la figura de la víctima en España. Filtrados estos datos fuertes por algunos paseos, aún inconclusos, por las evidencias empíricas de los mundos de vida de las víctimas, pueden proponerse cinco rasgos mayores de la "víctima española":

1) Un dato histórico. El propio de lugares que se piensan marcados por fenómenos recientes y extraordinarios (guerras, terremotos, violencia política...) que han producido efectos traumáticos de tal calibre que tras ellos es necesario repensar el núcleo mismo de la comunidad nacional y de la solidaridad y el pacto sociales, y re-construirlas (Piper, 2005; Gatti, 2014). La víctima es central en esas políticas de re-construcción y es central asimismo en las narrativas que se asocian con ellas.

2) Un personaje: que no es ya (o no es solo) la víctima singular (héroe, mártir), la víctima, en fin, como sujeto que por efecto de un hecho imprevisto se ve sustraído del común, sino todos aquellos (necesariamente muchos) que se ven afectados por la ola que genera el cataclismo, casi podría decirse que la comunidad entera, que en el límite deviene "comunidad de víctimas". Así, la víctima puede no ser ya un personaje excepcional, sino una red que reúne a sujetos ordinarios.

3) Una gestión del dolor (pública y no pública): una poderosa empatía con el que sufre que toma forma en expresiones de fuerte corporalidad (i.e.: "ponerse en el lugar del otro"), y algo que se asemeja a una pulsión hacia el cuidado del sufriente parecen ser los lugares desde los que se argumenta en esta región la solidaridad con dolor de otros. Sin excluir argumentos de equidad o justicia social (à la francesa), ni manifestaciones intensas de 
sensibilidad por el individuo que es porque sufre (à la anglosajona), padecer con y atender a son las piezas del engranaje de esta forma local de gestión de las víctimas.

4) Un lugar de legitimidad: lo físico, el cuerpo, la sangre, el ADN y, sobre todo, la familia; en suma, lo biológico. La víctima se define en muchos sentidos desde una matriz biologicista: (1) víctima es quien sufre y su cuerpo se resiente y es por eso vulnerable; (2) la solidaridad con la víctima consiste en poner el propio cuerpo en el lugar del que sufre; (3) el lazo familiar, sanguíneo, con la víctima (tenerlo y no tenerlo) define escalas de legitimidad y de reparación, organizaciones políticas, tipos de narrativas (Vecchioli, 2005; Vinyes, 2009; Sosa, 2011).

5) Una estética: que está cerca del pathos barroco y de sus tradiciones expresivas (la exageración, el recargamiento, la literalidad, el tremendismo, la exhibición, también la ironía o la parodia, no pocas veces el grotesco...). Es una puesta en escena terminal, agonista, sanguínea, corporal, en ocasiones tendente a la sordidez y lo humoral (véase sobre esto el texto de Josebe Martínez en este dossier).

¿Son estos rasgos propios solamente de la víctima española? No, evidentemente no, aunque es cierto que en España se manifiestan con especial intensidad y frecuencia. Aunque también en otras formaciones sociales similares ¿ ¿íctima latina quizás? No parece una categoría muy precisa, no para el rigor(ismo) de un sociólogo, aunque no pocas investigaciones indican que hay algo de específico de España o de América Latina en algunas formas de representar el lazo social (rasgo 4) y en ciertos recursos expresivos, propios de ciertas tradiciones (rasgo 5). Pero no es la de "víctima latina" una buena categoría. Entonces, ¿del sur? Si por sur entendemos estructuras sociales inestables, con marcas fuertes de sus pasados coloniales o periféricos, propensas a la refundación y a la construcción de narrativas asociadas a ellas, quizás sí, sí al menos en lo que hace al rasgo número 1 , ausente en las víctimas de lugares de fuerte institucionalidad, como los que delimitan geográficamente las dos aproximaciones dominantes en esta materia, y, al contrario, tediosamente repetido en lugares de institucionalidad débil, sometidos al vaivén permanente de la narrativa transicional, o de la de lo post- (sociedades postviolentas, postdictatoriales, postcoloniales) y tendentes, en definitiva, a la refundación periódica de sus pactos nacionales, pactos en los que tropos como la memoria o personajes como la víctima devienen centrales para (re)construir sus respectivas narrativas nacionales. Miren si no el lugar de las Madres y Abuelas de Plaza de Mayo en Argentina, de las víctimas en general en Colombia, de las víctimas de ETA en España... Jugando con ese contenedor, más geopolítico que geográfico, el sur, damos con un concepto ancho, muy ancho: Argentina, Uruguay, Brasil o Chile se alían con Camboya o Sudáfrica, que se juntan con España, Serbia o Irlanda, que invitan a Rwanda, Irak o Ingusetia y a Colombia o México. Demasiado amplio para servir, demasiado variado... Y tampoco del todo útil, pues ese contenedor, dejando fuera lo que ocurre en el ombligo del monstruo, desconsidera la evidente proliferación de víctimas asociadas a las demandas de reconocimiento (étnicas, 
históricas, de género...) que atraviesan estos países, los que no son del sur aunque tengan sures: víctimas del esclavismo, víctimas LGTB, minorías étnicas y un infinito etcétera.

Conviene quizás reorientar la mirada y trabajar, más que con cortes de orden geográfico o asociados a coordenadas culturales, hacerlo con otros temporales. Podría decir entonces que la de la víctima que falta por pensar es una cuestión de época ${ }^{17}$, la nuestra, a la que las dos grandes aproximaciones, muy ligadas a principios de trabajo con el vulnerable y el excluido fundantes de ese monigote tan útil llamado modernidad, no se adaptan del todo. Este personaje raro, ambiguo, negro y luminoso, único y colectivo, pasional y práctico, requiere de un corpus teórico nuevo, menos nacional y más bizarro, y hasta bastardo. Queda trabajo por hacer para conformarlo.

\footnotetext{
${ }^{17}$ A adoptar esa dirección me empujan los comentarios recibidos en algunos foros en los que he podido presentar estas ideas. En particular, debo citar las sugerencias que Jaume Peris Blanes y Jean Paul Zuñiga me hicieron llegar en las discusiones que sostuvimos en el encuentro Sangre y filiación en los relatos del dolor (Bilbao, mayo de 2014).
} 


\section{Referencias bibliográficas citadas}

Agier, Marc (2008). Gérer les indésirables. Des camps des réfugiés au gouvernement humanitaire. París: Flammarion.

Beristain, C.arlos y Páez, Darío. (2000). Violencia apoyo a las víctimas y reconstrucción social. Madrid: Fundamentos

Butler, Judith (2006). El poder del duelo y la violencia. Buenos Aires: Paidós.

Calzado, Mercedes Celina. "Violencia urbana y subjetividades victimizantes: sentidos y experiencias organizativas de las víctimas de la inseguridad en Argentina". Papeles del CEIC (2014/2).

Casado, Elena y García Selgas, Fernadno (2010). Violencia en la pareja. Donostia: Talasa.

Casado-Neira, David. "Las marcas en el cuerpo de la víctima: la veracidad encarnada en la violencia de género". Kamchatka 4 (2014): 359-380.

Chaumont, Jean-Michel (1997). La concurrence des victimes. Génocide, identité, reconnaissance. La découverte/Poche.

Das, Veena. (2008). Sujetos del dolor, agentes de dignidad. Bogotá: Pontificia Universidad Javeriana.

Dodier, Nicholas y Barbot, Janine (2009). "Itinéraires de réparation et formation d'un espace de victimes autour d'un drame médical". Périlleux, T. y Cultiaux, J. (eds). Destins politiques de la souffrance Toulouse: ERES.

Erner, Guillaume (2007). La société des victimes. París: La Découverte

Fassin, Didier (2010). La raison humanitaire. Une histoire morale du temps présent., París: Gallimard-Seuil.

Fassin, Didier y Richard Rechtman (2011). L'empire du traumatisme. París: Flammarion.

Ferrandiz, Francisco (2013). El pasado bajo tierra. Exhumaciones contemporáneas de la guerra civil. Barcelona: Anthropos.

Garapon, Antoine y Salas, Denis. "La victime plutôt que le droit". Esprit (11/ 2007) : 74-82.

Gatti, Gabriel (2008). "Oiga señor profesor, y si el Leviatán ya no existe, ¿para qué la teoría sociológica?". VVAA. Lo que hacen los sociólogos. Homenaje a Carlos Moya Valgañón. Madrid: CIS.

Gatti, Gabriel (2010). "Comunidades precarias en los universos sociales del detenido-desaparecido: los "hijos de", vástagos bastardos traicionando progenies, huérfanos paródicos consumiendo Historia”. P. de Marinis, G. Gatti, I. Irazuzta (eds.) La comunidad como pretexto. En torno al (re)surgimiento de las solidaridades comunitarias Barcelona: Anthropos. 
Gatti, Gabriel. "Moral Techniques. Forensic Anthropology and Its Artifacts for Doing Good". Sociología y tecnociencia: Revista digital de sociología del sistema tecnocientífico $1 / 3$ (2013).

Gatti, Gabriel (2014). Surviving forced disappearance in Argentina and Uruguay. Identity and Meaning. Nueva York: Palgrave MacMillan. DOI: $10.1057 / 9781137394156$

Girard, René (1982). Le bouc émissaire. París: Grasset.

Jimeno, Myriam (2008). "Lenguaje, subjetividad y experiencias de violencia". Das, V. et al. Sujetos del dolor, agentes de dignidad. Bogotá: Pontificia Universidad Javeriana:169-190.

Latté, Stéphane (2008). Les victimes. La formation d'une catégorie sociale improbable et ses usages dans l'action collective. Tesis doctoral inédita. Paris: EHESS. París.

Laugier, Sandra (2012). Tous vulnérables. París: Payot.

Lefranc, Sandrine y Mathieu, Lilian, eds. (2009). Mobilisations de victimes. Rennes: Presses Universitaires de Rennes.

Llera, Francisco y Retortillo, Alfredo, eds. (2004). Los españoles y las víctimas del terrorismo. Madrid: CIS.

Mate, Manuel Reyes (2002). La filosofía después del Holocausto. Barcelona: Riopiedras.

Martínez, Josebe. "La víctima en el mundo hispánico. Su definición a través del paradigma barroco". Kamchatka. Revista de análisis cultural 4 (2014): 341-358.

Merklen, Denis. (2010). Pobres ciudadanos. Las clases populares en la era democrática (Argentina 1983-2003). Buenos Aires: Editorial Gorla.

Paugam, Serge, ed. (1996). L'exclusion, l'état des savoirs. París: La Découverte.

Paugam, Serge y Schultheis, Franz (1998). "Introduction" a Georg Simmel Les pauvres. París: PUF.

Perez-Sales, Pau y Navarro, Susana. (2007). Resistencias contra el olvido. Barcelona: GEDISA.

Piper, Isabel (2005). Obstinaciones de la memoria: la dictadura militar chilena en las tramas del recuerdo. Tesis doctoral. Universidad Autónoma de Barcelona, Barcelona.

Rodríguez Yagüe, Cristina (2000). La mujer como víctima. Ciudad Real: UCLM.

Sánchez-Carretero, Cristina (2006). "Trains of Workers, Trains of Death". VVAA. Spontaneous Shrines and the Public Memorialization of Death. Nueva York: Palgrave. 
Simmel, Georg (1998). Les pauvres. París: PUF.

Sosa, Cecilia (2011). "Queering acts of mourning in the aftermath of Argentina's dictatorship: The Mothers of Plaza de Mayo and Los Rubios (2003)". Druliolle, V. and Lessa, F. (eds.) The Memory of State Terrorism in the Southern Cone: Argentina, Chile, and Uruguay. Nueva York: Palgrave.

Vecchioli, Virginia (2005). "La nación como familia. Metáforas políticas en el movimiento argentino por los derechos humanos". Frederic, S. y Soprano, G. (comps.). Cultura y Política en Etnografias sobre la Argentina. Buenos Aires: UNQ/Prometeo.

Vinyes, Ricard. (2009) "Sobre víctimas y vacíos: ideologías y reconciliaciones; privatizaciones e impunidades". Ana Domínguez Rama (eda.). Enrique Ruano: Memoria viva de la impunidad del franquismo. Madrid: Editorial Complutense: 255-272.

Wieviorka, Michel. “L'émergence des victimes”. Sphera Pública 3 (2003): 19-38.

\section{Filmografia:}

Arabia, Sebastián (2010). Un largo invierno. Madrid. 